\title{
ORIGENS DA INTEGRAÇÃO DO CONE SUL: COMÉRCIO E CONTRABANDO
}

\author{
Francisco de Borja B. de Magalhães Filho ${ }^{1}$
}

\section{INTRODUÇÃO}

Este artigo procura analisar as causas, conseqüências e, principalmente, as características de que se revestiu o processo de surgimento de relações comerciais significativas e duradouras entre os estabelecimentos espanhóis e portugueses onde hoje são os países da Bacia do Prata, desde os primórdios da colonização. Essas relações, muitas vezes ilegais, principalmente nos períodos dos monopólios reais e das políticas mercantilistas adotadas por ambas as metrópoles, desempenharam papel importante na consolidação da ocupação territorial e no crescimento das atividades econômicas desses estabelecimentos.

Por outro lado, essas relações foram também fundamentais, mesmo para além do período colonial, para o crescimento econômico de algumas regiões dos estados soberanos que surgiram na primeira metade do século XIX. De certa maneira, podem ser vistas, a partir de nosso olhar atual, como os primeiros e distantes passos rumo a uma crescente integração econômica entre esses países, situados no que hoje chamamos de Cone Sul. Mas devem, sobretudo, ser analisadas como um conjunto de estratégias de sobrevivência e de expansão, decorrente da necessidade de atender demandas próprias e de superar dificuldades criadas pelas regras impostas por Portugal e Espanha. Essas regras, coerentes com a fase inicial de expansão dos interesses do capital mercantil europeu, afetavam, de formas diferenciadas, as atividades econômicas e a própria sobrevivência de cada um desses estabelecimentos.

As estruturas produtivas e as relações comerciais surgidas nessas regiões, como resultado da imposição dessas regras - quer obedecendo-as, quer desafiando-as por meios ilícitos (principalmente pelo contraban-

\footnotetext{
${ }^{1}$ Professor do Departamento de Economia da UFPR.
} 
do) - à medida que se consolidavam, viriam a ser entendidas por alguns autores, quando analisadas à luz dos estudos, pesquisas e formulações teóricas sobre os conceitos de desenvolvimento e de sua contrapartida, o subdesenvolvimento (iniciado a partir de meados do século XX), como conformando um tipo especial na tipologia das economias primário-exportadoras surgidas em decorrência da expansão colonial.

Para Osvaldo Sunkel e Pedro Paz (1970), por exemplo, ao referirem-se ao funcionamento do modelo colonial espanhol, diferenciam o tipo de economia dessas colônias em relação aos núcleos centrais, centros coloniais, que denominam de tipo C (México e Peru). São classificadas como economias de subsistência - tipo S (Chile e noroeste da Argentina, por exemplo), ou como áreas vazias - tipo V (Pampa argentino e os campos da margem esquerda do Uruguai). Segundo esses autores

Si para ilustrar este criterio tomamos el caso del sistema colonial que tiene su centro en el Virreinato de Lima, regiones como Chile, Ecuador y el Noroeste argentino, corresponderían aproximadamente al tipo $\mathrm{S}$ de economías de subsistencia. En estas regiones se establecen el gobierno, la burocracia y las fuerzas armadas metropolitanas, que, para su consumo, requieren una evolución de la agricultura de subsistencia, en el sentido de transformala, por lo menos en parte, en agricultura excedentária. Esto posibilita, a su vez, el desarrollo de cierta actividad comercial, particularmente en lo referente a productos agropecuarios que interesan a Lima y al Alto Peru: cueros, sebo, trigo, vino, aceite, mulas. etc.(...)

Por outra parte, en las áreas vacías (economia de tipo V) como el Rio de la Plata, se establece una burocracia militar y administrativa com el fin de limitar el contrabando y la penetración de las otras potencias en el territorio colonial. En este caso, las formas de vinculación se dan a través del financiamiento de la burocracia colonial por parte del Virreinato y de un pequeño intercambio comercial entre el área y el resto del Virreinat (SUNKEL; PAZ, 1970, p. 285).

Ainda que o texto não apresente análise tão detalhada em relação ao sistema colonial português, tal como estruturado no Brasil, faz-lhe rápidas referências, o que cabe analisar. Introduz, por exemplo, o surgimento de "otro tipo de economia. basada en la exportación de productos agrícolas de plantación, tales como el azúcar, el cação, el café y el tabaco”, produtos que desempenharam papéis de importância significativa em momentos diferentes da história da economia brasileira. Esse outro tipo de economia 
distingue-se por "apresentar condiciones de desarrollar una actividad exportadora con productos que también interesan desde el punto de vista mercantilista". Nesses casos, ao lado da agricultura de subsistência, "surgiria otra comercial del tipo plantation o hacienda, y también una actividad comercial". A esse tipo de economia os autores denominam de SP, ou seja, uma variante que combina as características das economias centrais, com seu quase-monopólio da produção e exportação de determinados produtos, com uma especialização na produção e exportação de produtos agrícolas tropicais, tipo plantation, com as encontradas nas economias de subsistência (SUNKEL; PAZ, 1970, p. 288).

Por um lado, cabe discordar da aplicação dessa denominação às economias açucareira e cafeeira, pelo menos no caso brasileiro. O papel que claramente desempenham, tanto no período colonial (no caso do açúcar) quanto após a transformação do país em estado soberano (com a expansão inicial da economia cafeeira) foi, sem dúvida o de economias centrais. Por outro lado, é certamente válida para a produção de fumo, cuja expansão atendeu à demanda gerada pelo crescimento do tráfico de escravos, e poderia ser aplicada à expansão do cacau no sul da Bahia, por mais que esta, ainda que com características típicas de economia primário-exportadora, só viesse a se expandir no século XX.

Analisando também a tipologia das economias primário-exportadoras decorrentes da expansão colonial promovida pelos interesses do capital mercantil, Fernando H. Cardoso e Enzo Faletto (1970), identificam dois tipos distintos: as colônias de população e as colônias de exploração. As primeiras têm um papel que corresponde aproximadamente aos núcleos centrais, tipo C de Sunkel e Paz, só que analisado pelo ângulo de sua influência futura sobre

as possibilidades de integração nacional e de formação de um mercado interno se comparadas às "colônias de exploração", por serem formadas sobre a exploração (controlada por produtores ali radicados) de produtos que requerem mão-de-obra abundante.(...) Ademais, a própria base física da economia - como, por exemplo, o tipo e a possibilidade de ocupação da terra ou o tipo de riqueza mineral disponível - influirá sobre a forma e as conseqüências da vinculação ao mercado mundial posterior ao período de formação nacional (CARDOSO; FALETTO, 1970, p. 35).

No que se refere às colonias de exploração, o texto é menos preciso, e orientado mais para referir-se ao seu papel futuro: limita-se a afir- 
mar que "A formação nacional nas antigas colônias 'de exploração' - corno as áreas de mineração - ou em regiões marginais à corrente principal do mercado colonial teve menores possibilidades de êxito no século XIX" (CARDOSO; FALETTO, 1970, p. 41).

Os enfoques diferentes adotados nos dois trabalhos citados não traduzem interpretações conflitantes sobre a tipologia das economias coloniais. O papel desempenhado pela mineração de prata (Peru e México), ouro e diamantes (Brasil), e cana-de-açúcar (Brasil, Pequenas Antilhas, Haiti e Cuba) traduz-se tanto no conceito de colônias centrais quanto no de colônias de povoamento. O mesmo pode ser dito, com ressalvas, em referência aos de economias de subsistência e de colônias de exploração. No primeiro caso, pelo já comentado papel das economias açucareira e cafeeira no Brasil, cujo papel é muito mais tipo $\mathrm{C}$ do que SP; no segundo, pela inclusão não diferenciada do termo áreas de mineração, uma vez que esta atividade, em muitos casos, caracterizou economias tipo $\mathrm{C}$ ou colônias de povoamento, e não de exploração - pela definição destas apresentadas no texto. Quanto às áreas vazias, tipo $\mathrm{V}$, da tipologia de Sunkel e Paz, mesmo não sendo citadas diretamente por Cardoso e Faletto. podem ser identificadas por eles entre as chamadas regiões marginais, restando a contradição de que o Pampa Argentino e o Uruguai, ainda que marginais até o final do século XVIII, foram as que apresentaram maior êxito no século XIX.

Uma terceira análise, apresentada a partir de enfoque diferente, encontra-se no texto de Ciro Flamarion Cardoso e Héctor Pérez Brignoli (1983, p. 75 et seq.), que descreve quatro situações concretas, de cuja combinação podem ser construídas diversas tipologias aplicáveis às economias coloniais. As quatro situações são: 1- Segundo as potências colonizadoras, de pouca relevância para os objetivos deste artigo; 2 - Segundo o grau de vinculação ao mercado mundial, onde os autores incluem o que chamam zonas subsidiárias voltadas para o mercado local ou intercolonial, exemplificando-as com as atividades pecuárias no Brasil (ainda que mencionando somente as do interior nordestino, voltadas para o mercado da economia açucareira) e a produção chilena de trigo, vendida para o Peru, que correspondem às economias de subsistência - tipo $S$ e às colônias de exploração; 3 - Segundo os tipos de produção, onde são novamente citadas as colônias que produzem alimentos para os mercados da América, exemplificadas, entre outras, pelas atividades econômicas do Chile, e das regiões pecuárias do Nordeste e do Sul do Brasil; 4 - Segundo a questão da mão-de-obra e do caráter da colonização, com destaque para o fato de que onde as condições naturais eram próximas às das zonas temperadas da Europa, após serem conquistadas e confiscadas as terras dos indígenas, consti- 
tuíram-se colônias de povoamento a partir de uma imigração européia mais ou menos importante (às vezes já em pleno século XIX, fora portanto da época colonial), surgindo sociedades euro-americanas, sendo citada como exemplo a região dos pampas. Este último conceito é, sem dúvida, aplicável às sociedades que se constituíram na Bacia do Prata, principalmente no que se refere ao Uruguai, a grande parte da Argentina e ao sul do Brasil.

Esse conjunto de estudos sobre a tipologia das economias coloniais permite identificar melhor o marco histórico em que se inserem as economias da Bacia do Prata no período colonial, assim como melhor entender suas dificuldades e possibilidades de expansão econômica, a partir de suas diferenças em relação às economias centrais ou colônias de povoamento, onde as exportações de alto valor ou em grandes quantidades eram altamente lucrativas para as metrópoles, e as políticas mercantilistas que estas seguiam, absolutamente voltadas para os interesses associados a esse sistema de exploração.

São essas economias,

cujos interesses somente eram lembrados pelas metrópoles na medida em que atendiam de alguma forma aos dos centros coloniais, que podem ser chamadas de economias primárioexportadoras de segunda ordem, derivadas de outras economias primário-exportadoras, pois suas bases produtivas são criadas, ou reorganizadas, a partir desses centros colônias (...) e não diretamente pelas metrópoles ou seus capitais mercantis (MAGALHÃES FILHO, 1999; p. 13).

Essa classificação não significa, e isso se confirma no caso aqui estudado, que o capital mercantil, controlado e estimulado pelas cortes espanhola e portuguesa (esta cada vez mais associada aos interesses mercantis da Inglaterra, principalmente após a Restauração, em 1640), não tivesse interesse por essas colônias. O que ocorria parece decorrer principalmente o fato de que

Las condiciones del transporte, su elevado costo y sus frecuentes riesgos, orientaron la política colonial hacia la extracción de metales preciosos o de artículos muy escasos y de gran valor. Por ellos existía demanda en los mercados europeos $y$ solían encontrarse en regiones tropicales. La aventura marítima era demasiado costosa para orientar las inversiones hacia otras actividades (...). El desarrollo tecnológico valorizaría tan sólo mucho mas tarde los productos de las zonas templadas (CONDE; GALLO, 1967, p. 12). 
Essa avaliação traduz, sem dúvida, o que possivelmente é o principal fator explicativo do alheamento do capital mercantil em relação às atividades produtivas e comerciais relacionadas com esse tipo de colônia, como a exportação de carne e trigo do Chile para o Peru, ou de erva-mate do Paraguai para Buenos Aires e o Chile: pequena magnitude e maior lucratividade, se comparadas à mineração da prata ou à produção de açúcar. Razões suficientes para não atrair, a não ser marginalmente, sua participação ou controle direto. Isso, de um lado, significava para elas sua marginalização no cenário da exploração colonial; de outro, abria caminho para que nelas se criassem sistemas de relacionamento fora dos marcos legais impostos pelas metrópoles.

\section{O QUADRO INICIAL: ISOLAMENTO E CONTATOS ESPORÁDICOS}

É importante lembrar que as regiões mais diretamente envolvidas nessas relações comerciais, exatamente por serem colônias cujas economias permitem classificá-las como primário-exportadoras de segunda ordem, desempenharam papéis secundários nas atividades econômicas espanholas e portuguesas na América do Sul, pelo menos até o final do século XVIII.

Para a Espanha, toda a atenção se concentrava na sua colônia central, o Peru, principalmente na exploração da prata em Potosí, no Alto Peru, e nas atividades a ela associadas. Seguindo suas próprias concepções mercantis, todo o comércio com as colônias centrava-se em Sevilla, onde se localizou inicialmente a Casa de Contratación de las Indias, posteriormente transferida para Cádiz. Na América do Sul, estava concentrado em Lima, que o monopolizava, com Paita, no norte do Peru, que servia a Lima no início da colonização, e depois também Callao, como os portos de chegada e partida dos galeões que faziam a ligação com o Panamá e, via Portobelo, com Sevilla, única rota inicialmente autorizada para o comércio com a metrópole. O sistema de frotas anuais (nem sempre regulares), utilizado pelos espanhóis para garantir tanto a segurança do transporte marítimo, frente a piratas, corsários e navios inimigos, quanto o monopólio da Coroa e dos comerciantes de Sevilla e Lima, limitava a freqüência e as rotas dos navios. Apenas algumas das regiões administradas pelo Vice-Reinado, como o Chile e Cuyo (no atual noroeste da Argentina), podiam inicialmente atender, e só com seu próprios produtos, a demanda da região argentífera de Potosí.

Toda essa presença do estado espanhol, na principal de suas colônias na América do Sul, não conseguia impedir o contrabando. Quando, 
por exemplo, o almirante inglês Anson ocupou e saqueou Paita, em 1741, surpreendeu-se com a quantidade de ouro e prata que encontrou, pertencente a contrabandistas que utilizavam o porto para enviá-la ilegalmente para o Panamá (MADARIAGA, 1955; p.188).

A região do Prata apresentava condições de rota alternativa secundária para o comércio com a Europa, mas sua utilização era proibida. $\mathrm{O}$ Rio da Prata fora descoberto antes do $\mathrm{Peru}^{2}$ e a primeira, e fracassada, fundação de Buenos Aires, em 1536, é contemporânea da conquista do Império Inca por Pizarro, em 1533. Mas com toda a atenção voltada para o Peru, o limitado sucesso inicial espanhol no Prata resumiu-se à fundação de Assunção (1537) e de outros pequenos estabelecimentos como Corrientes, em 1558 e Santa Fé, em 1573, ao longo dos grandes rios navegáveis. A fundação definitiva de Buenos Aires só se daria em 1580. Por todo esse período, e até 1776, toda a região era parte do Vice Reinado do Peru, e judicialmente dependente da Audiencia de Lima.

Paralelamente, os interesses portugueses no Brasil estiveram principalmente voltados, até o final do século XVII, para a produção e exportação de açúcar, no litoral que vai de Potengi ao Recôncavo Baiano. Ainda que os limites estabelecidos em Tordesilhas fossem várias vezes desrespeitados, principalmente na Amazônia e na bacia do Alto Paraná, na direção sul só foram ultrapassados após a fundação de Laguna, em 1673, e com o estabelecimento da Colônia do Sacramento, em 1680.

Nesse quadro, o território que separava as possessões espanholas e portuguesas na região do Prata permaneceu como área não ocupada pelos colonizadores, ainda que atravessada ou explorada esporadicamente por expedições oficiais ou privadas, até o século XVII. Por outro lado, isso não impediu o desenvolvimento de ligações comerciais marítimas, legais ou não, esporádicas e transitórias, entre os portos platinos e brasileiros, como se verá adiante.

A primeira tentativa de ocupação e colonização espanhola para o leste, para além do rio Paraná, iniciou-se no século XVI e, por quatro décadas do século seguinte, aproximou-se o bastante dos estabelecimentos portugueses de São Vicente e São Paulo para ser contatada e atacada por expedi-

${ }^{2}$ Em 1516, pela expedição espanhola comandada por Solis. Há indícios que havia sido explorado uns dez anos antes por expedição portuguesa, possivelmente a chefiada por Cristovão Jacques, que o haveria tomado como abertura marítima para o Pacífico e, portanto, à Asia. (ZWEIG, 1938). Informações desse tipo são freqüentes, e importantes, por desmentirem a história oficial. Esse é o caso do descobrimento casual do Brasil em 1500, quando, na realidade, o litoral nordestino já fora visitado, em 1498, pelo cosmógrafo e navegante português Duarte Pacheco Pereira (PEREYRA, 1949, p. 61). 
ções privadas de predadores (bandeirantes) de índios. Esses ataques levaram ao abandono do território, retraindo-se os espanhóis para o Paraguai.

Essa expansão, a partir de Assunção, alcançara e ultrapassara o rio Paraná, com a fundação de Ontiveros, na margem direita, em 1554, e de Ciudad Real del Guayrá, já na outra margem, próxima às Sete Quedas, em 1556, e avançara pelo vale do Ivaí, com a fundação de Villa Rica del Espíritu Santo, em 1557. O processo acelerou-se com a criação da Província Jesuítica do Paraguai, em 1609, com o que passou à responsabilidade da Companhia de Jesus a ocupação do território e a administração das reduções, isto é, dos núcleos criados para concentrar a população indígena convertida (em grande maioria da nação guarani), bem como a gestão de suas atividades produtivas e suas relações comerciais.

Em pouco tempo haviam sido criadas 23 reduções, na região que abrange desde as margens do Paranapanema (onde foi estabelecida a primeira, na foz do Pirapó, em 1610), ao norte, até o Iguaçu, ao sul, e ao Tibagi, a leste. ${ }^{3}$ Outras reduções foram sendo criadas, nessa época, no sul do Paraguai e no que hoje são as províncias argentinas de Corrientes e Misiones, até as margens do rio Uruguai.

Esse processo expansivo, ao ocupar espaços ainda não colonizados entre as possessões espanholas e portuguesas, aproximou-as, gerando os primeiros conflitos. Estes, por sua vez, decorreram principalmente das mencionadas incursões das bandeiras vicentinas que percorriam a área, tanto em busca de metais preciosos quanto a prear índios, para vendê-los como escravos em São Vicente e São Paulo. Foi a partir de 1628 que os bandeirantes passaram a atacar as reduções, principalmente as situadas entre o Paranapanema e o Iguaçu, pois os indígenas ali capturados, já familiarizados com a vida sedentária e o trabalho agrícola, obtinham melhor preço nos mercados do litoral. ${ }^{4}$

Os sucessivos ataques vicentinos levaram à evacuação, no início da década de 1630, de toda a região mencionada, com a fuga ou transferência da população indígena para novas reduções, os chamados Sete Povos, no noroeste do que hoje é o Rio Grande do Sul. ${ }^{5}$ A região entre o Paranapanema

${ }^{3}$ Há controvérsias quanto ao número de reduções, possivelmente decorrente de características ou funções diferentes. As reconhecidas por todos foram 13 (ver, por exemplo, LUGON, 1968, MAACK, 1968, e MARTINS sd.).

${ }^{4}$ Parte significativa dos indígenas escravizados como resultado desses ataques era revendida para economia açucareira do Nordeste, onde eram aproveitados, pelo seu preço mais baixo, para substituir os escravos africanos em atividades outras que não a produção, o beneficiamento e o transporte de açúcar (SIMONSEN, p. 214).

${ }^{5}$ Ao mesmo tempo em que, obtendo os jesuítas autorização papal para armar os índios, estes impõem fragorosa derrota aos preadores em Mborore, na margem direita do Uruguai, em 1641 (SIMONSEN, p. 212). 
e o Iguaçu permaneceu, a partir desse êxodo, praticamente desabitada até o século XIX (MAACK, 1968).

É importante considerar que as reduções chegaram a ter, com fortes flutuações, população total estimada entre 200 mil e 300 mil habitantes, o que era significativo nessa época, considerando que Buenos Aires e o Paraguai, somados, não chegavam ainda a essa última cifra ao final do século XVIII (LUGON, 1968, p. 78 et seq.).

Essa economia semiautônoma, criada e gerida pelos jesuítas, viria a desempenhar, como será visto mais adiante, importante papel na Bacia do Prata, principalmente no que se refere à erva-mate e, inicialmente em escala menor, à criação e comércio de animais. Seu fim ocorreu já na segunda metade do século XVIII, quando a Província foi extinta, e os jesuítas expulsos, primeiro por Portugal, em 1758, depois pela Espanha, em 1767. Essa expulsão foi o resultado de antigas pressões dos proprietários de terra e comerciantes espanhóis, apoiados por outras ordens religiosas, contra o poder político e econômico de que a Ordem se beneficiava pelo seu monopólio da exploração da Província, bem como por suas interferências nas relações de trabalho entre os índios e os encomenderos e nas administrações reais das regiões vizinhas. Seu apoio, suposto ou real, à resistência armada dos índios das reduções, principalmente os que habitavam os Sete Povos, e a intervenção militar conjunta de Portugal e Espanha, destinada a fazer cumprir a transferência das missões da margem esquerda do Uruguai para Portugal, uma das cláusulas do Tratado de Madrid, de 1750, foi a gota d'água que levou os governos dos dois países à sua expulsão e, finalmente, à extinção da Ordem por Bula Papal em 1773. A Ordem só seria novamente reconhecida pelo Papado em 1814.

Paralelamente a isso, iniciara-se, já desde o século XVI, a gradual ocupação das terras litorâneas na direção sul, a partir do primeiro centro de colonização portuguesa, a Capitania de São Vicente. Esse processo foi motivado por três razões principais: a primeira, a procura de novas terras para cultivo, à medida que crescia a população nas áreas já ocupadas; outro fator igualmente importante, ainda que limitado a algumas áreas, foi a descoberta de ouro de aluvião em alguns dos rios que descem da Serra do Mar para o litoral, como em Cananéia e na Baia de Paranaguá e; finalmente, após o processo de ocupação atingir a Linha de Tordesilhas, a existência, para além de Laguna e Torres, de terras disponíveis em escala muito maior, o que dá início à ocupação das planícies a partir da bacia do Guaíba para o sul, entrando nos 
pampas, onde viria a ser o Rio Grande do Sul. ${ }^{6}$ Aqui, mais do que nas terras costeiras primeiramente ocupadas, a criação animal viria a ser predominante.

Enquanto esses dois processos se desenrolavam, as atividades econômicas dos estabelecimentos espanhóis na região às margens do Prata e de seus formadores enfrentavam grandes dificuldades para desenvolverse, tolhidas pela política colonial espanhola. Esta, como já mencionado, privilegiava a mineração da prata de Potosi e o monopólio real concedido aos comerciantes de Lima, dificultando ou limitando os fluxos comerciais, quer pelas rotas fluviais e terrestres de Buenos Aires (e do Paraguai) para os centros de mineração do Altiplano, quer por via marítima, inclusive com a própria metrópole.

Por outro lado, ambos os processos de ocupação mencionados lançaram as bases das atividades econômicas que, a partir do final do século XVII, criariam condições para o surgimento e consolidação de um sistema de intercâmbio econômico - muitas vezes ilegal, principalmente aos olhos das autoridades espanholas - que não só dinamizaria o comércio em toda a região, como levaria a um longo período de guerras e definições de fronteiras, cujas causas e resultados serão posteriormente mais detalhados.

Essas guerras, em que questões econômicas e de definição de fronteiras se combinavam, iriam estender-se até meados do século XIX. Interessante é o fato de que, apesar de sua freqüência, pelo menos no que se refere ao século XVIII, não seriam empecilho para a consolidação do comércio. A produção e comercialização de erva-mate e o comércio de animais e seus produtos seriam as primeiras atividades a expandir-se, transformando-se nas principais atividades econômicas da Bacia, como analisaremos mais adiante.

\section{COMÉRCIO MARÍTIMO: ESCRAVOS E CONTRABANDO}

Antes disso, e apesar dos obstáculos iniciais já mencionados, veio sendo criada, desde o final do século XVI, uma teia de relações comercias que, gradativamente, foi contornando ou vencendo as normas estabelecidas pela Espanha. Isso surgiu de um crescente comércio terrestre, alimentado pela expansão do comércio marítimo - ambos em grande parte inicialmente ilegais, mas posteriormente legalizados e regulamentados - principalmente com os portos brasileiros.

${ }^{6}$ Com a vantagem de que, para além de Laguna, em terras oficialmente espanholas, não mais era preciso, inicialmente, obter concessões de sesmarias da Coroa portuguesa, sendo a terra simplesmente ocupada. 
O comércio marítimo pelos portos do Prata foi inicialmente proibido, de forma indireta, pela regulamentação estabelecida pela Espanha, em 1560, com respeito à operação dos galeões. Mas, “en 1594 se imitió la cédula que en representación de los poderosos comerciantes de Sevilla y de Lima, establecia una definitiva prohibición" (MORNER, 1968, p. 25) Ainda que mantida a proibição do comércio direto com a metrópole, o período entre 1580 e 1640, em que o rei da Espanha o era também de Portugal, levou, ainda que de forma limitada e controlada, à legalização do comércio marítimo entre o Prata e os portos do Brasil.

Segundo Puiggros, a primeira anotação registrada no Libro de Tesoreria de Buenos Aires, datada de 1587, inaugurando o seu papel como porto aberto ao exterior, registra a exportação de prata de Potosi e panos de Tucumnán destinados a portos brasileiros, em navio enviado pelo bispo dessa última cidade (PUIGgros, 1945, p. 21). Nesse período, segundo Morner, Buenos Aires exportava para o Brasil farinha, panos de algodão, gorduras animais (sebo) e vinhos, importando principalmente sedas, ferro e escravos africanos, "mercancia esta última cuya demanda en Potosi había alcanzado singular magnitud" (PUIGGRos, 1945, p.25).

A magnitude dessa demanda fez com que o governo espanhol outorgasse, em 1595, licenças para o tráfico a dois comerciantes portugueses (que as mantiveram até 1609) autorizando a importação anual, via porto de Buenos Aires, de 600 escravos, "de los que, al parecer, pocos permanecieron en la región del Plata donde el número de quienes podian adquirirlos era bastante reducido" (PUIGGROs, 1945, p.25).

Só em 1602 é que foi concedido, por um período de seis anos, aos comerciantes de Buenos Aires o direito de comerciar, com seus próprios navios, com os portos do Brasil e das colônias africanas de Portugal, excluindo-se a importação de escravos. Em 1618 essa concessão foi reduzida a dois navios por ano, mas com autorização para vender produtos nos portos brasileiros, comprar produtos locais, revendendo-os em Sevilha, e ali adquirir bens destinados aos mercados do Rio da Prata.

Todas essas limitações ao comércio externo da região traduziramse em forte incentivo para o contrabando, inclusive de escravos. Como afirma Morner (1968, p. 26):

El alcance dei comercio ilegal practicado a través de Buenos Aires entre los portugueses y el Alto Peru puede ser deducido del hecho de que, durante da década de 1620, el contrabando confiscado constituyó la principal fuente de ingresos de la Caja Real del Rio de la Plata. 
Puiggros, ao analisar alguns dados dessa época, confirma a importância do comércio marítimo entre o Prata e o Brasil (legal ou ilegal) durante o século XVII. Cita, por exemplo, 370 portugueses vivendo em Buenos Aires em 1662, para um total de 1.200 habitantes (PUIGGROS, 1957, p. 180). Cita, também, dados sobre o comércio exterior de Buenos Aires, que mostram, entre 1586 e 1655 importações no valor total de 1,5 milhão \$ prata (excluídos os escravos), contra exportações de 366 mil \$ prata, o que, segundo o autor, comprova que a diferença era coberta com pagamentos em prata de Potosí (Puiggros, 1957, p. 182).

Mas, pelo menos até o século XVIII, o aspecto mais importante desse comércio foi a importação de escravos dos portos brasileiros. Puiggros (PUIGGRos, 1957, p. 185) realça as razões econômicas desse tráfico ao afirmar que "el comercio portugués proporcionó, además, la mano de obra tan reclamada en el litoral, al introducir esclavos negros que se aplicaban a la economia doméstica". A partir do início desse século, a Espanha autorizou a uma companhia francesa (Companhia da Guiné) e, posteriormente, a uma inglesa (South Sea Company) a estabelecer asientos ${ }^{7}$ em Buenos Aires, respectivamente em 1701 e 1716, passando a praticamente monopolizar esse comércio, vendendo escravos trazidos diretamente de seus estabelecimentos situados na costa africana, o que aponta para a oficialização, ainda que limitada, dos contatos diretos com o capital mercantil não espanhol.

\section{A ERVA-MATE}

Dos dois processos mencionados no início deste artigo, o primeiro a se desenvolver foi o da economia ervateira. Quando da chegada dos espanhóis e da fundação de Assunção, a erva-mate já era conhecida e utilizada pela população do Paraguai, principalmente pelos guaranis, ${ }^{8}$ sendo seu consumo generalizado em todo o território entre os rios Paraguai e Paraná, nas áreas ribeirinhas da margem esquerda deste último, na bacia do Alto Uruguai, e, para o norte, até próximo ao Pantanal Matogrossense (LINHARES, 1969, p. 3).

${ }^{7} \mathrm{O}$ asiento era uma autorização contratual que estabelecia prazos, direitos e deveres específicos para a pessoa física ou jurídica, que a recebia da Coroa, exercer legalmente suas atividades.

${ }^{8}$ Sobre os sistemas de trabalho e de troca entre os guaranis na produção do mate, ver Roulet, 1993. 
Em pouco tempo, o hábito de consumo de mate, sob as diversas formas de preparo criadas pelos guaranis, e utilizando os utensílios por eles desenvolvidos, foi sendo incorporado pelos europeus, espalhando-se logo para além das regiões onde era originalmente extraído e consumido. Na medida em que os jesuítas foram criando suas reduções, a maior parte da produção e do comércio de erva-mate passou a ser controlada por eles, transformando-se no principal bem exportado pela Província Jesuítica para os outros estabelecimentos espanhóis do Cone Sul. Note-se que foram dos jesuítas as primeiras tentativas de cultivar a erva-mate. Sabe-se que os resultados favoráveis quanto à qualidade do produto assim obtido, um tipo de erva que passou a ser chamado de caamini, permitiam que fosse vendida a preços duas ou três vezes maior do que os alcançados pela tradicional, de palos (LINHARES, p. 24 et seq.).

Nos estabelecimentos portugueses a penetração do consumo de mate deu-se de forma mais lenta. Primeiro, por meio de contatos, a princípio apenas esporádicos, logo permanentes, entre os habitantes dos pampas do Rio Grande do Sul e os das margens esquerdas do Uruguai e do Prata, nos campos de preação e criação de animais, principalmente após a fundação da Colônia do Sacramento (1680) e da vila de São Pedro do Rio Grande do Sul (1737). ${ }^{9}$ Mais tarde, com a chegada dos portugueses à região central de Mato Grosso, para a exploração dos aluviões auríferos, a partir de 1719, e com a lenta expansão dessa ocupação rumo ao sul, onde havia extensos ervais, e o decorrente contato com os guaranis, o consumo de mate consolidou-se na nova Capitania, separada de São Paulo em 1744.

Mesmo com a já mencionada extinção da Província Jesuítica e a expulsão da Ordem pelo governo espanhol, o Paraguai continuou como maior produtor de erva-mate, e principal fornecedor para os demais centros consumidores do Prata, de Cuyo e do Chile, ainda que tenha atravessado uma fase de queda na qualidade e na produção. ${ }^{10} \mathrm{~A}$ produção brasileira, menor, ainda era principalmente limitada ao consumo das regiões produtoras, como em Mato Grosso e nos planaltos e vales do $\mathrm{Sul}^{11}$, ainda que os

${ }^{9}$ A data refere-se ao primeiro estabelecimento português no local, o Forte do Estreito. A vila propriamente dita só foi criada em 1751.

${ }^{10}$ Muitos autores confirmam essas quedas, principalmente Lugon (p. 127) e Linhares (p. 44 et seq.).

${ }^{11}$ Ou seja, em sua maior parte, da Capitania de São Paulo, uma vez que, até a criação da Capitania de São Pedro do Rio Grande, excluída a região costeira de Santa Catarina, essa capitania estendia-se até a fronteira Meridional do Brasil (SIMONSEN, p. 230 et seq.). 
crescentes mercados da Banda Oriental e do Rio Grande já houvessem criado uma demanda permanente de mate originário dessas áreas produtoras.

Essa rápida análise confirma o que disse um estudioso das relações econômicas da região do Prata:

La yerba mate fué una de las principales mercancías objeto del comércio en el coloniaje. Su centro de producción estaba radicado donde todavía lo está hoy: el Paraguay y los territórios ocupados por los jesuitas, que alcanzaban hasta lo que son hoy los estados brasileños de Paraná, Santa Catarina y Rio Grande do Sul. Su transporte abrió caminos y vias fluviales que todavía hoy están en uso (MAGAlHãES, 1945, p. 12).

O quadro anteriormente referido mudaria a partir do início do século XIX, como veremos mais adiante, principalmente pelos conflitos que se seguiram à independência dos países envolvidos, inclusive as guerras, não só entre eles, mas também entre as províncias argentinas. A Guerra do Paraguai será a última delas, mas seus resultados mudariam definitivamente o comércio do mate.

\section{PREAÇÃO, CRIAÇÃO E COMÉRCIO DE ANIMAIS E SEUS PRODUTOS}

O segundo dos processos já referidos surgiu lentamente, desde o século XVII, como decorrência da gradual ocupação dos pampas do Rio Grande, de São Pedro e da Banda Oriental. Nesse amplo território viviam os charruas, povo nômade, cujo principal sustento vinha da coleta e da caça (principalmente de nhandus), utilizando as boleadeiras como arma. Com a chegada dos europeus, ou pelas margens do Uruguai, ou ao longo da Lagoa dos Patos, trazendo bovinos, cavalos e mulas, e como as condições em que se dava a criação, em campo aberto, favorecia-lhes a fuga, surgiram rebanhos de animais tresmalhados, originários principalmente das reduções. Os charruas foram os primeiros beneficiários, capturando-os e dominando as técnicas de montaria. À medida que crescia a população de origem européia, aumentavam a preação - captura de animais bravios - e a criação, mas ambas vagarosamente, até que a crescente demanda de outras regiões coloniais 
pressionou os preços dos couros bovinos e dos animais de carga, principalmente no que se refere aos muares. ${ }^{12}$

No que se refere ao couro, sua produção nessa região começara a expandir-se ao final da segunda metade do século, acompanhando a tendência que já se verificava em Buenos Aires, Santa Fé e Entre Rios nas décadas anteriores. Essa expansão decorria principalmente da crescente demanda européia. Para Simonsen, foi a preocupação da Coroa em manter a primazia no comércio de couros, aliada à de estender os seus domínios até o Prata, que levaram-na, deliberadamente, a fundar a Colônia do Sacramento (SIMONSEN, 1957, p. 172). A sua localização facilitava o contrabando da produção que descia pelos rios - afirmando, também, que não é exagero afirmar que essa época do couro no extremo Sul começou com a fundação da Colônia do Sacramento, pois sua presença estimulou a produção nos pampas do Uruguai e da Campanha gaúcha. Puiggros (1945, p. 31) concorda com essa análise, afirmando que

Portugal ocupó esse lugar (...) con el propósito de dominar el intenso tráfico que se realizaba con el cuero y estar en condiciones de adquirirlo directamente al gauchaje, sin pasar por la fiscalización de las autoridades españolas, comentando também que La Colonia del Sacramento estuvo abierta por otra parte, a los navios ingleses, asociados a Portugal en esos negócios.

O comentário final retrata a crescente importância da associação de Portugal com os interesses do capital mercantil inglês.

$\mathrm{O}$ abate de bovinos para a retirada do couro gerou, por sua vez, outras atividades, como a produção e exportação de sebo e de charque. Todos esses produtos não só eram exportados para a Europa e para Cuba, como também para outras capitanias. Segundo Prado Júnior (1956, p. 98), o charque ganhara importância ao final do século XVIII:

seu aparecimento no comércio da colônia coincidiria com a decadência da pecuária nos sertões do Nordeste, incapazes já de atender às necessidades do mercado (...) em 1793 a capitania (do Rio Grande) já exportava 13000 arrobas de charque, nos primeiros anos do século seguinte alcançará quase 600.000 , comentando que: Excluído o rush do ouro, não se assistira ainda na colônia a tamanho desdobramento de atividades.

12 Segundo estudos sobre a economia das estâncias nos pampas da bacia do Uruguai, no século XVIII, "los precios de los animales de silla y tiro, caballos y muares, son en general superiores a los de las reses vacunas" (CARAVAGLIA, 1978). 
No caso do charque, o interessante é que a técnica de seu preparo foi transferida para as charqueadas da Campanha gaúcha por cearenses especialistas em carne-de-sol, vindos de sua Capitania: "Foi o cearense José Pinto Martins, um dos retirantes da sêca de 1777-78, quem fundou no Rio Grande do Sul a indústria do charque (...) em 1780 (...) a carne era preparada segundo o sistema nortista" (SOUSA DOCCA, 1954, p. 109).

Mas o principal fluxo comercial da região foi o que fortaleceu, desde o início do século XVIII, as relações comerciais não só do Rio Grande do Sul e do Uruguai, mas também de Corrientes e, em menor escala, de Entre Rios, com o Centro-Sul do Brasil: a criação de muares para atender a demanda nas Minas Gerais.

A descoberta de ouro em Caeté, 1693, e no Rio das Velhas, poucos anos depois, seguidas dos sucessivos achados de outros aluviões auríferos, provocou um forte fluxo migratório que, somado à crescente aquisição de escravos para as atividades mineradoras, alimentou rapidamente a população da região, elevada a Capitania das Minas Gerais em 1720. Onde antes praticamente inexistiam populações de origens européia ou africana, em menos de meio século o número de habitantes ultrapassou os 700 mil. $\mathrm{O}$ mesmo, ainda que em escala menor, ocorreu nas novas regiões auríferas, onde viriam a ser as capitanias de Goiás e Mato Grosso.

Surgia nessa região uma nova economia primário-exportadora do tipo C (centros coloniais) de Sunkel e Paz, ou colônia de população de Cardoso e Faletto, de acordo com as tipologias vistas no início deste trabalho. É uma economia que pelo valor de seus produtos de exportação (ouro e diamantes) rivalizaria com o até então único centro colonial do país, a economia açucareira.

Sendo a mineração um trabalho permanente, ao contrário, por exemplo, do cultivo e beneficiamento da cana-de-açúcar, de caráter sazonal, os escravos dedicavam-se exclusivamente a ele. Isso levou a que a produção e importação de alimentos, bem como a maior parte das atividades urbanas, atraíssem parte significativa desse fluxo migratório. À medida que a produção crescia, e a riqueza aumentava, e se estabelecia um padrão de urbanização até então praticamente inexistente no Brasil, a demanda das lavras e das cidades e vilas não só exigia cada vez maior quantidade de importações de outras regiões, como dependia de transporte terrestre pelas rotas longas e difíceis que a ligavam a seus portos, principalmente o do Rio de Janeiro, cuja importância econômica e estratégica começava então a manifestar-se.

Ora, dada a topografia da região, principalmente nas rotas que a ligavam aos portos, essa expansão dependia totalmente de animais, mais 
precisamente mulas, para o transporte dos produtos importados. Ainda que parte (pequena) dessa demanda fosse atendida por outras regiões (principalmente o interior do Nordeste, via Rio São Francisco) a Campanha gaúcha e os pampas da Banda Oriental foram, desde o início, os principais fornecedores desses animais, principalmente quando se abriu o chamado Caminho do Viamão.

A principal fornecedora localizava-se desde as margens orientais das lagoas dos Patos e Mirim e, para além do Jaguarão, na direção sul, estendendo-se para oeste na direção da margem esquerda do Uruguai. As primeiras exportações de animais para o Rio de Janeiro foram feitas por mar, a partir de Laguna. $\mathrm{O}$ custo elevado e o alto índice de perdas registrados nessas viagens levaram a expedições em busca de um caminho terrestre.

Em 1730, por iniciativa do governador da Capitania de São Paulo, organizou-se expedição oficial, que abriu o chamado Caminho do Viamão, por onde as tropas, adquiridas no extremo sul pelos tropeiros, ${ }^{13}$ em grande parte residentes na Comarca de Curitiba, eram levadas, para revenda, à grande feira anual realizada em Sorocaba. A maior vantagem oferecida por esse caminho era a possibilidade de aproveitar, para descanso e engorda, os campos de Vacaria, Lages e Curitiba.

O primeiro apogeu dessa atividade deu-se no terceiro quartel do século XVIII, quando o movimento em Sorocaba teria atingido cerca de 200 mil animais por ano (SIMONSEN, 1957, p.179). ${ }^{14}$ A partir daí, a queda da produção de ouro empobreceu as regiões de mineração, reduzindo drasticamente a demanda por animais. Esta voltou a crescer a partir da terceira década do século XIX, devido à expansão da economia cafeeira no vale do Paraíba. Nesse novo período, não só tornou a crescer o movimento de tropas pelo Caminho do Viamão, como ganhou importância o caminho que, dos planaltos paranaenses atingia o Alto Uruguai e, dali, a região criadora da Província de Corrientes (PINHEIRO MACHADO, 1969).

A importância do papel das relações comerciais do Brasil com o Prata nesse comércio é reconhecido por Prado Júnior (1956, p. 101), quando afirma que "o Rio Grande exporta, por terra naturalmente, de 12 a 15.000

13 O termo "tropeiro" significa, aqui, o empreendedor que viaja com seus parentes e agregados até o extremo Sul, compra os animais, formando uma "tropa", e a conduz até o mercado onde a venderá. Diferente do significado do mesmo termo, dominante no restante do Brasil, onde é utilizado para referir-se ao dono, ou guia, de animais que prestam serviços de transporte, a médias e longas distâncias, de mercadorias alheias.

${ }^{14}$ Esse número parece exagerado, se referido ao século XVIII. Como é citado, atribuído a JJ. Élise Réclus, cuja obra é posterior ao segundo apogeu, é possível que tenha sido atingido no século XIX. 
bêstas por ano em princípio de século passado, mas é difícil apurar quantas destas são naturais da capitania, e quantas contrabandeadas do Prata". ${ }^{15}$

É interessante, nesse contexto, analisar a evolução da criação e do comércio de animais das estâncias das margens do Uruguai, antes geridos pelos jesuítas, e que entrou em forte decadência ao longo da desaceleração do primeiro processo expansivo da demanda brasileira por muares. Apenas parte dessa decadência pode ser atribuída a essa desaceleração, posto que essa região atendia também os mercados rioplatenses.

A melhor explicação está em que, à medida que a gestão dessas atividades passa das mãos dos índios às de funcionários espanhóis, a imposição de exigências maiores no sistema de trabalho, após gerar forte aumento da produção, levou, segundo Caravaglia (1978, p. 468 et seq.),

\begin{abstract}
a la destrucción paulatina de las comunidades indígenas En efecto, en los veinte años siguientes, una cantidad inusitada de productos de las misiones entran en el mercado rioplatense, decayendo ese ritmo poco después como resultado del agotamiento y destrucción de la mano de obra indígena (...) Ese auge productivo tuvo lugar gracias (...) al aumento del tiempo de trabajo supuestamente destinado a la comunidad, con el consiguiente refuerzo de la coacción extraeconómica. Los pueblos verán un último y aparente esplendor, para desaparecer finalmente en las primeras décadas del siglo siguiente.
\end{abstract}

A decadência definitiva do tropeirismo se deu a partir de meados do século XIX, quando o transporte de mercadorias nas regiões cafeeiras passa a ser cada vez mais feito pelas estradas de ferro, reduzindo-se drasticamente a demanda por mulas. (MAGALHÃES FILHO, 1996, p. 134; 1999, p. 86).

Deve-se ter em mente que o pano de fundo da expansão do tropeirismo, na sua primeira fase, foi o rápido crescimento da economia brasileira provocado pela magnitude da proibição de ouro, quando o Brasil se transformou no maior produtor mundial, sem esquecer a de diamantes, quando alcançou posição semelhante, produtos ambos extraídos da mesma macroregião. De um lado, esses fatos traduziram-se no deslocamento do centro dinâmico da economia colonial do Nordeste para o Centro-Sul, com aumento da presença das instituições da Coroa, principalmente as militares

${ }^{15} \mathrm{O}$ autor utiliza o termo bêstas referindo-se a mulas. 
e as fiscais, levando, inclusive à transferência da sede do Governo Geral de Salvador para o Rio de Janeiro (1763). ${ }^{16}$

De outro, deram início a um processo de crescimento que levaria a Colônia a equiparar-se à sua metrópole em população e no valor das exportações. No que se refere à economia, os dados do comércio português da época são a este respeito meridianamente claros. "Cerca de $2 / 3$ da exportação do Reino para outros países se fazia com mercadorias da colônia. E isso sem incluir os valores do ouro e dos diamantes" (PRADO JR, 1956, p. 121).

Outro fato que traduz a importância do tropeirismo, no seu primeiro apogeu, mantida - ainda que por pouco tempo - no início do segundo, é o peso relativo dos tributos sobre as tropas vindas do Sul na receita da Capitania, depois Província de São Paulo, como mostra Simonsen (1957, p. 177) citando o trabalho Ensaio dum quadro estatístico da província de São Paulo, realizado em 1838, no qual verifica-se que, de uma receita provincial total presumível, em 1835-1836, estimada em 292 contos-de-réis, 111 provinham dos pagamentos efetuados como direito de passagem das tropas pelos chamados registros de Curitiba (Rio Negro e Guarapuava) e 22 pelos impostos cobrados sobre as vendas na feira de Sorocaba, perfazendo um total de 132 , ou seja, $45 \%$ da receita total. O autor comenta, em seguida, que para se aferir da repercussão política de tal comércio, basta citar que uma das causas apontadas para a Revolução dos Farrapos, em 1835, fora a desses direitos de entrada do gado rio-grandense nas outras províncias, transcrevendo partes do texto do Manifesto da República Rio-Grandense de 1835:

Tiram-nos o dízimo do gado muar e cavalar e o substituem pelos direitos de introdução às outras províncias. Não os pagam onerosos em Santa Vitória, escandalosos no Rio Negro, insuportáveis em Sorocaba, pontos precisos de trânsito de nossos tropeiros nos mercados de São Paulo, de Minas e da Corte? (SIMONSEN, p. 197).

Se esse documento destaca o importante papel dos recursos financeiros gerados por esse comércio para a economia rio-grandense, a inclusão de Santa Vitória, por sua localização, confirma, por sua vez, a forte participação dos animais de origem platina que entravam pela fronteira com o Uruguai.

${ }^{16}$ Uma das razões dessa transferência foi também o entendimento dessa cidade como lugar mais próprio para acudir as guerras do Sul (FLEIUSS, 1925). 
Por outro lado, e já em meados do século XIX, os dados existentes mostram que parte das exportações de couros e charque do Uruguai pelo Rio Grande do Sul, provavelmente pelas melhores condições operacionais então apresentadas por seu porto, passaram a dar-se via Montevidéu. "Entre 1856 y 1858, por ejemplo se exportaron por el puerto de Montevideo 300000 cueros anuales, de los cuales el 50\% pertenencian al litoral argentino y Rio Grande del Sur. El 25\% del tasajo enviado a Cuba y Brasil eran de las mismas procedências" (BARRAN, 1998, p. 71). Esses dados mostram que, sem especular qual a percentagem desses produtos que era contrabandeada, os fluxos comerciais na fronteira meridional do Brasil eram efetivamente de duas mãos.

\section{INCORPORAÇÃO DA BACIA DO PRATA AO COMÉRCIO MUNDIAL}

As últimas décadas do século XVIII e as primeiras do seguinte foram acompanhadas, como conseqüência direta dos processos econômicos e políticos que se manifestavam na Europa Ocidental, de mudanças qualitativas nos marcos referenciais do comércio internacional, mudanças essas que, obviamente, iriam modificar sua forma e seu conteúdo, bem como a identidade de seus principais atores, no âmbito das relações comerciais entre os países do Prata e o Brasil, e destes com as potências comerciais européias e, posteriormente, com os Estados Unidos.

As primeiras mudanças decorreram do Tratado de Madrid, de 1750, em que Portugal e Espanha redefiniram as fronteiras entre suas colônias na América do Sul obedecendo (aproximadamente) o critério da ocupação permanente do território. No que se refere às fronteiras sulinas, Portugal ganhou os campos ao sul da Lagoa Mirim, assim como as terras ao norte do Ibicuí, à margem esquerda do Uruguai, incluindo a região dos Sete Povos das Missões, abrindo mão, em troca, da Colônia do Sacramento (esta perdera parte de sua importância em decorrência da fundação de Montevidéu, em 1725).

Esse Tratado foi anulado em 1761 (em parte como decorrência da já mencionada resistência armada dos índios das reduções). Pelo Tratado de San Ildefonso, em 1777, Portugal abriu mão dos campos ao sul do Chuí e do território dos Sete Povos, mas a fronteira definitiva somente seria fixada, já após o período colonial, em decorrência dos acordos que puseram fim à guerra da Cisplatina, em 1830. ${ }^{17}$

${ }^{17}$ Os Sete Povos foram reanexados em 1801. Em 1811, o exercício português invadiu a banda Oriental a pedido do general Elío, comandante das forças espanholas, 
Essa guerra, que redundou na independência do Uruguai, foi um dos muitos conflitos militares que caracterizaram, por mais de meio século, toda a região do Prata ao longo de todo esse período.

No caso da Argentina, após sua independência, os conflitos surgiram principalmente entre Buenos Aires e as outras províncias, principalmente devido à dificuldade de consenso sobre o modelo constitucional a ser adotado - confederação ou federação - que traduzia a disputa sobre a quem caberia o controle do porto da cidade de Buenos Aires e de sua alfândega, e das receitas por ela geradas, e que desempenhava ainda papel estratégico como único porto marítimo. Essa disputa, somada aos interesses específicos de cada província, postergaram a consolidação do estado nacional, levando a casos extremos de exercício de soberania estatal por algumas delas, como "Corrientes, al firmar como Estado soberano un tratado con Uruguay, o Entre Rios y Corrientes al aliarse a Uruguav y Brasil en 1851" (CHIARAMONTE, 1993, p.120). Essa situação só seria superada após a aprovação da Constituição de 1853, não aceita por Buenos Aires, e da vitória militar desta na batalha de Pavón, em 1861.

Para além das disputas internas da Argentina, e envolvendo os outros países da Bacia do Prata, outras causas podem ser identificadas, principalmente as questões como a dos direitos de navegação nos rios da Bacia e as freqüentes intervenções brasileiras (que deram continuidade à política portuguesa iniciada em 1811, com a ocupação e anexação da chamada Banda Oriental) e bonaerenses sobre seus vizinhos.

A última e mais importante dessas guerras foi a que levou à derrota e ocupação do Paraguai pela Tríplice Aliança, em 1870, após cinco anos de conflito que arrasaram o país, provocando a morte de três quartos de sua população. ${ }^{18} \mathrm{~A}$ esses conflitos, de caráter eminentemente regional, devem somar-se os bloqueios e ações navais decorrentes de intervenções européias, que causavam fortes prejuízos ao comércio, e que, quaisquer que fossem os motivos alegados, traduziam o claro objetivo de fortalecer e ampliar sua

incapazes de deter os revolucionários uruguaios apoiados por Buenos Aires. Retiradas depois de um armistício que reconheceu a autoridade espanhola, os portugueses voltaram a invadir o Uruguai, em 1816, anexando-o ao Brasil em 1821. A fronteira, que retornara ao Ibicuí, só foi finalmente fixada no Quaraí em 1830, como decorrência das reposições entre o Brasil e a Argentina, sob mediação britânica, que reconheceram a independência uruguaia.

${ }^{18}$ Sobre a política intervencionista do Império no Prata, entre 1822 e 1876 , incluindo as causas e conseqüências da Guerra do Paraguai, ver CERVO; BUENO, 1992. 
presença comercial na região. ${ }^{19}$ Esta começara lentamente, restrita a autorizações específicas, com limites quantitativos e temporais, acelerando-se a partir do levantamento definitivo das proibições e restrições impostas desde o início pelas políticas mercantilistas, já mencionadas, praticadas pelas duas metrópoles.

No Prata, esse processo desenrola-se lentamente, a partir da criação do Vice-reinado, em 1776, consolidando-se apenas em 1810. No Brasil, a chamada Abertura dos Portos é uma decorrência lógica da transferência da Corte para o Rio de Janeiro, com apoio inglês, em 1808. A partir daí, em processo contínuo, ainda que muitas vezes conflituoso, e em escalas diferentes em cada país, a presença do comércio e dos capitais das potências comerciais européias tenderá a crescer, principalmente a inglesa.

\section{MATE E DIVERSIFICAÇÃO COMERCIAL: O SÉCULO XIX}

Como já foi mencionado, a primeira e principal mudança se deu, inicialmente, no comércio ervateiro, ainda nas últimas décadas do período colonial. Como afirma um dos autores já citados "al pasar las tierras situadas en las márgenes izquierdas del Alto Paraná y del Uruguay al dominio portuguéz, cayeron bajo ese dominio muchos yerbales y el comercio de la yerba pasó a internacional" (MAGALHÃES, 1945, p. 12). Como não podia deixar de ser, as décadas de conflitos antes mencionadas provocaram alterações significativas nos fluxos de erva-mate, tanto a cancheada quanto a beneficiada. ${ }^{20}$ Ao interromper ou dificultar os fluxos comerciais tradicionais, elevando os preços nos mercados importadores, esses conflitos prejudicaram diretamente o Paraguai, e isso antes mesmo dos estragos provocados pela Guerra da Tríplice Aliança. As sucessivas interrupções e crescentes riscos na navegação nos principais rios da Bacia levaram os importadores de Buenos Aires a procurarem alternativas, o que abriu caminho para as exportações

${ }^{19}$ Uma esquadra francesa bloqueou Buenos Aires entre 1838 e 1840 , em decorrência de uma disputa com o governo de Rosas, ocupando a ilha de Martin Garcia e intervindo no Uruguai; em 1845 uma esquadra conjunta franco-britânica interveio na chamada Guerra Grande (1843-1851), entre Rosas e Oribe, de um lado, e Rivera do outro, capturando a esquadra rosista e bloqueando a ligação entre Oribe e Buenos Aires.

${ }^{20}$ Cancheada e beneficiada são as duas formas tradicionais em que o mate é produzido e comercializado entre países. A primeira resume-se à poda, secagem, trituração manual e embalagem, inicialmente em surrões de couro, mais tarde em barricas. A segunda corresponde a uma atividade industrial, onde a secagem e a trituração são feitas por meio de máquinas, em estabelecimentos industriais. 
brasileiras, principalmente do Paraná, do norte de Santa Catarina e do Rio Grande do Sul e, mais tarde, de Mato Grosso, para os mercados do Prata e para o Chile.

Já a partir de 1820, negociantes de Buenos Aires montaram casas exportadoras em Paranaguá, ou mudaram-se para esse porto, ao tempo em que comerciantes locais passavam também a exportar. Um importador argentino, Francisco Alzagaray, é celebrado como quem transmitiu o conhecimento técnico necessário para que a erva-mate cancheada paranaense alcançasse os padrões de qualidade e sabor requeridos pelo mercado platino (MAGALHães FILHO, 1999, p. 92)

Em torno de meados do século, principalmente quando a Guerra da Tríplice Aliança interrompeu o comércio com o Paraguai, começou a expandir-se, com capitais locais, o que viria a ser a indústria do mate. Isso ocorreu com a incorporação de máquinas e técnicas decorrentes dos avanços das forças produtivas nos países já industrializados, com a introdução dos moinhos a vapor, ou com a adoção de práticas como a moagem sistemática, a separação de goma, pó e talos, e das folhas de diferentes tamanhos, com a mistura controlada de elementos componentes dos tipos (diferenciados) destinados à Argentina, ao Chile e ao Uruguai (CARNEIRO, 1962, p. 105). Isso tornou possível o aumento da produtividade, e a exportação do mate industrializado pronto para o consumo, inclusive já embalado para venda no varejo com marcas próprias. ${ }^{21}$ Esse processo ocorreu não apenas no Paraná, mas também no Rio Grande do Sul e, ainda que mais tarde e em escala menor, no norte da Santa Catarina. Até então, a principal exportação catarinense para o Prata era a de farinha de mandioca (WestPHALEn, 1999, p. 130).

A partir do final do século XIX desenvolveu-se, no sul de Mato Grosso, outro processo de expansão econômica baseado na exportação de mate, mas com características diferentes do que vimos até agora. Trata-se da concessão, dada em 1891 à Companhia Mate Laranjeira, de monopólio para a exploração dos ervais da região, exportando o mate principalmente por Porto Murtinho, no rio Paraguai. A Companhia investiu também na exportação de madeira da margem esquerda do Paraná, onde construiria uma estrada de ferro (de Guaíra a Porto Mendes) para contornar as Sete Quedas. Tratavase de empresa sediada em Buenos Aires, controlada por capitais argentinos, associados a investidores britânicos, já na fase em que o capital estrangeiro estava presente em segmentos significativos das economias de todos os países da Bacia do Prata. Apesar de perder o monopólio em 1915, manteve,

${ }^{21}$ Sobre a importância das marcas para a manutenção e expansão dos mercados, ver Linhares, (p. 364). 
até 1949, o contrato de exploração com Mato Grosso, ainda que já abalada pela crise da economia ervateira, a qual analisaremos a seguir.

Por outro lado, desde a segunda metade do século XIX, as exportações do Rio Grande do Sul vinham declinando continuamente, transformando-o cada vez mais em importador, principalmente da erva paranaense (WESTPHALEN, 1999).

O apogeu da economia ervateira no Brasil dar-se-ia na década de 1920. Mas seria um apogeu com morte anunciada, posto que, desde a primeira década do século, a Argentina adotara políticas de fomento ao cultivo do mate (em Misiones) e de apoio à produção de erva-mate beneficiada no próprio país. Como se isso não bastasse, quando os ervais cultivados alcançaram produção significativa, iniciava-se a Grande Depressão, reduzindo o consumo e os preços, o que levou o governo argentino a adotar medidas protecionistas para defender o novo setor produtivo. Iniciada sua produção em 1910, com 910 toneladas, Misiones ${ }^{22}$ atinge 10 mil toneladas em 1925, 25.446 em 1930, e 106.330 em 1937 (GARCIA-MATTA; LLORENS, 1940).

Os resultados foram altamente negativos para a economia ervateira brasileira, traduzindo-se em um longo período de estagnação. As exportações sofrem forte queda, principalmente as destinadas ao mercado argentino. Praticamente, a partir do ano de 1933, deixou de sair do Brasil para a Argentina erva beneficiada, assim como, desse ano em diante, começou a queda vertiginosa da cancheada. De 50.000 .000 de quilos que era a exportação para aquele país em 1932, ela ficou na casa dos 30.000.000 até 1939. Daí por diante, passou para casa dos 20 e dos 10 (LINHARES, 1969, p. 363). O mesmo, ainda que em escala menor, deu-se com as exportações totais dos dois tipos: de 1926, quando se registrou a maior quantidade exportada, com 93 mil toneladas, as exportações reduzem-se para 60 mil, em 1939.

A economia ervateira sobreviveu, mas sua importância relativa declinou continuamente, tanto no que se refere à produção quanto, e principalmente, à exportação. "Se a comienzos de este siglo, en los años 1901, 1902 y 1903 , el valor de las exportaciones de yerba insumía alrededor del $75 \%$ de las exportaciones brasileñas a la Argentina (...) En 1940 (...) la yerba sólo llegó al 7\%" (MAGALHÃES, 1945, p. 51 et seq.).

A economia ervateira, exatamente por continuar circunscrita à mesma região pelo menos desde o século XVII, é a única sobrevivente desse período a manter-se ainda, mesmo com a atual mundialização, sem significativa participação de capitais externos. É óbvio que funciona integrada e é

${ }^{22}$ Os dados incluem uma parcela muito pequena cultivada no nordeste de Corrientes. 
afetada diretamente pelas novas formas de que se reveste o capital no plano mundial, continuando todavia a Argentina como o maior produtor (e sem importar cancheada) e o único em que a produção é proveniente do cultivo; o Brasil ainda é o maior exportador, seguido pelo Paraguai. Uruguai e Chile continuam importando: o Uruguai, os dois tipos, o Chile, só beneficiada.

Das outras atividades econômicas que participaram do estabelecimento e consolidação das relações comerciais entre as colônias da Bacia do Prata, só uma, obviamente, desapareceu por completo: o tráfico de escravos africanos. As demais sobreviveram, mas passando por mudanças significativas, principalmente devido à incorporação dos avanços das forças produtivas nos países desenvolvidos, que em maior ou menor tempo, foram logo adotados aqui. Foram mudanças na tecnologia, na organização do processo produtivo e, cada vez mais freqüentemente, na origem do capital.

Um exemplo significativo desses processos: no início da década de 1850, aproveitando-se da definitiva extinção do tráfico de escravos, e da conseqüente disponibilidade dos capitais nele envolvidos, que passaram a buscar aplicações alternativas, Irineu Evangelista de Sousa, então Barão de Mauá, com o apoio de suas ligações com grupos financeiros britânicos, constrói e controla um império empresarial, investindo em bancos, comércio exterior, ferrovias e empresas agrícolas e industriais, não só no Brasil, como na Argentina e, principalmente, no Uruguai. Neste último, o grupo não apenas concede grandes empréstimos ao governo quanto estabelece um estaleiro e uma empresa produtora e distribuidora de gás. Seu grupo chega à máxima expansão em meados da década de 1860, falindo ao final da seguinte, apesar de suas relações britânicas. Comentando o grande empréstimo feito pelo banco de Maná no Uruguai ao governo desse país, em 1865, onde constava cláusula que autorizava a revenda no exterior dos títulos públicos dados como garantia, Barran aponta para o fato de que a concretização dessa revenda - para bancos ingleses - havia sido, ao final, o único destino possível dessa integração financeira e dos empreendimentos de Mauá, comentando que: "El capital brasileño, en efecto, no podia financiarnos. Ese era un signo de la debilidad imperial y de que la hora llegaba para el capital inglés" (BARRAN, 1998, p. 124). E, pode-se acrescentar, um signo que traduzia a impossibilidade da continuidade da política intervencionista no Prata que caracterizara o Império desde a vinda da corte portuguesa para o Brasil. 


\section{CONCLUSÃO}

A impossibilidade do Império dar continuidade a políticas intervencionistas traduzia, também, a nova realidade gerada pelo avanço das forças produtivas nas potências européias, com o abandono das regras próprias ao mercantilismo, e a crescente expansão da presença direta dos capitais europeus nas finanças e nas atividades produtivas no interior dos países primário-exportadores, assim como na defesa do livre comércio.

Com efeito, o crescimento dos investimentos europeus (principalmente britânicos, franceses e alemães) e, ainda que em escala menor, norte-americanos, fizeram-se presentes em todas as principais atividades econômicas, quer na produção, no comércio exterior ou na intermediação financeira.

Um exemplo disso foi a expansão na produção animal. Quando, no início do século XX, cresceu a demanda européia por carnes bovinas e surgiram os primeiros frigoríficos, em poucos anos as grandes empresas do setor, como Anglo, Wilson, Armour e Swift começaram a investir tanto na Argentina quanto no Brasil, que logo se situaram entre os maiores exportadores mundiais. Em escala menor, o mesmo aconteceu no Uruguai e no Paraguai. Essa expansão da produção de carne bovina estimulou a produção de couros crus, mas esta, provavelmente devido à pequena escala requerida por suas unidades de produção, permaneceu predominantemente nacional. $\mathrm{O}$ charque transformou-se praticamente em produto de consumo interno. $\mathrm{O}$ virtual desaparecimento do comércio de mulas, dado o surgimento de meios de transporte mais eficientes, já foi mencionado anteriormente.

Ao iniciar-se o século XX, os processos que haviam gerado o comércio entre os estabelecimentos coloniais espanhóis e portugueses no século XVI já estavam esgotados, ou haviam sido superados. Os conceitos discutidos no início deste trabalho ou já haviam perdido, ou perdiam rapidamente, seu poder explicativo no que se refere ao funcionamento das economias envolvidas. De certa forma, passavam a ser temas para o estudo e a pesquisa no campo da história.

Por mais que esses países ainda pudessem ser classificados como primário-exportadores, pois seu dinamismo dependia, em última análise, de suas exportações de poucos bens primários (principalmente o Brasil), o crescimento alcançado por seus mercados internos já vinha estimulando e permitindo o surgimento de setores produtivos voltados principalmente para atender essa crescente demanda (principalmente no Brasil e na Argentina). Essa nova situação já afetara também cada uma das regiões aqui citadas 
como economias primário-exportadoras de segunda ordem, na medida em que a integração nacional de cada uma as vinculava a um comércio interno cada vez mais dinâmico, e que a exploração de novos setores produtivos oferecia-lhes oportunidades para conquistar mercados externos. No Rio Grande do Sul, por exemplo, a crescente exportação de carne bovina para a Europa; na Região Sul como um todo, a entrada no mercado de madeira branca (araucária) não só no mercado interno como no Prata e, posteriormente, na Europa.

Esse novo cenário, ainda no campo do subdesenvolvimento, já trazia em si a possibilidade de romper com a dependência das exportações primárias. A depressão dos anos trinta e a também mundial que a sucedeu antecipariam esse rompimento. Passar-se-iam ainda algumas décadas para que o desenvolvimento econômico desses países, e as dificuldades que enfrentavam em suas inserções na economia mundial, os levassem a negociar a criação de mecanismos de integração, agora abrangendo a totalidade de cada um, e não apenas as terras onde colonos espanhóis e portugueses, tolhidos pelas regras impostas por suas cortes, haviam, no passado já então distante, criado entre si vínculos econômicos que lhes permitiram sobreviver e crescer.

\section{RESUMO}

Este trabalho tem como objetivo levantar e analisar as atividades econômicas que se desenvolveram no processo de formação, expansão e integração dos estabelecimentos coloniais de caráter secundário, criados por Espanha e Portugal na Bacia do Prata, e sua evolução no que se refere ao comércio entre eles, ao longo do período colonial. $\mathrm{O}$ que se procura destacar é como, apesar das restrições impostas pelas metrópoles, principalmente a Espanha, mas também Portugal, esses estabelecimentos criam mecanismos de contatos comerciais entre si - alguns à margem das leis vigentes - consolidando e fortalecendo seus sistemas produtivos, com pouco ou nenhum apoio das administrações coloniais, e sem participação direta significativa do capital mercantil europeu. Objetiva-se, também, analisar o destino desses sistemas produtivos no século XIX, à medida em que se integram às recém-formadas economias nacionais, então fortemente dependentes dos mercados e capitais internacionais.

Palavras-chave: Cone Sul, metrópoles coloniais, integração, comércio. 


\begin{abstract}
This article aims at identifying and analysing the economic activities that were involved in the process of development, expansion and integration of the colonial settlements of secondary importance founded by Spain and Portugal in the River Plate's estuary and basin, and the evolution and growth of their trade among them, through the colonial period. In fact, the main objective is to analyse how, even with the restrictions imposed by the colonial metropolis, those settlements established forms of commercial contacts among them - sometimes without respecting the laws in force - that consolidated and strengthen their own productive system, with none or limited backing from the colonial administration, and without significant direct participation of European mercantile capital. Another objective is to analyse what happened with those productive systems in the nineteenth century, as they are integrated in the just formed national economies, at the time strongly dependent of international markets and capitals.
\end{abstract}

Key-words: South Cone; colonial metropolis; integration; commerce.

\title{
REFERÊNCIAS
}

BARRAN, José Pedro. Apogeo y crisis del Uruguay pastoril y caudillesco. Montevideo: Banda Oriental/La República, 1998.

CARAVAGLIA, Juan Carlos. Las actividades agropecuarias en el marco de la vida económica del pueblo de indios de Nuestra Señora de los Santos Reyes Magos de Yapeyú: 1768-1806. In: FLORESCANO, Enrique. (Org.) Haciendas, latifundios y plantaciones en América Latina. México: Siglo Veintiuno, 1978. p. 464-485.

CARDOSO, Círo F.; BRIGNOLI, Héctor P. História econômica da América Latina. Rio de Janeiro: Graal, 1983.

CARDOSO, Fernando H.; FALETTO, Enzo. Dependência e desenvolvimento na América Latina. Rio de Janeiro: Zahar, 1970.

CARNEIRO, Davi. Fasmas estruturais da economia do Paraná. Curitiba: UFPR, 1962. CERVO, Amado Luiz; BUENO, Clodoaldo. História da política exterior do Brasil. São Paulo: Ática, 1992.

CHIARAMONTE, José Carlos. El federalismo argentino en la primera mitad del siglo XIX. In: CARMAGNANI, Marcello. (Org.). Federalismos latinoamericanos: México, Brasil y Argentina. México: EI Colegio de México/Fondo de Cultura, 1993. p. 81-132. CHIAVENATO, Julio José. Genocídio americano: a Guerra do Paraguai. São Paulo: 
Brasiliense, 1979.

CONDE, Roberto Cortes; GALLO, Ezequiel. La formación de la Argentina moderna. Buenos Aires: Paidos, 1967.

FLEIUSS, Max. História administrativa do Brasil. São Paulo: Melhoramentos, 1925.

GARCIA-MATA, Rafael; LlORENS, Emilio. Argentina econômica. Buenos Aires: Impresora Argentina, 1940.

KROEBER, Clifton B. La navegación de los rios en la historia argentina. Buenos Aires: Paidos, 1967.

LINHARES, Temístocles. História econômica do mate. Rio de Janeiro: José Olympio, 1969.

LUGON, C. A república comunista cristã dos guaranis. Rio de Janeiro: Paz e Terra, 1968.

MAACK, Reinhard. Geografia física do Estado do Paraná. Curitiba: Badep/UFPR/ IBPT, 1968.

MADARIAGA, Salvador de. El auge del império espanhol en América. Buenos Aires: Sudamericana, 1955.

MAGALHÃES FILHO, Francisco de B. B. de. Evolução histórica da economia paranaense. Revista Paranaense de Desenvolvimento n. 87, jan./abr. 1996, p. 131-148.

. Da construção ao desmanche: análise do projeto paranaense de desenvolvimento. São Paulo, 1999. Tese (Doutorado em Sociologia) - Faculdade de Filosofia, Letras e Ciências Humanas, Universidade de São Paulo.

MAGALHÃES, Homero B. de. Argentina-Brasil: sentido de sus relaciones econômicas. Buenos Aires: Losada, 1945.

MARTINS, Romário. História do Paraná. Curitiba: Guaíra. s.d.

MORNER, Magnus. Actividades políticas y económicas de los jesuitas en el Río de la Plata. Buenos Aires: Paidos, 1968.

PEREYRA, Carlos. Breve história de América. México: Aguilar, 1949.

PINHEIRO MACHADO. Brasil. Sociedade campeira - gênero de vida. In: BALHANA, Altiva Pilatti et al. História do Paraná . Curitiba: Grafipar, 1969, p. 87-102.

PRADO JÚNIOR, Caio. História econômica do Brasil. São Paulo: Brasiliense, 1956.

PUIGGROS, Rodolfo. História económica del Rio de la Plata. Buenos Aires: Futuro, 1945.

De la colonia a la revolución. Buenos Aires: Leviatan, 1957.

ROULET, Florencia. La resistencia de los guaranís del Paraguay. Posadas: Unam, 1993.

SIMONSEN, Roberto C. História econômica do Brasil (1500-1820). São Paulo: Companhia Editora Nacional, 1957.

SOUSA DOCCA, Emilio Fernandes de. História do Rio Grande do Sul. Rio de Janeiro: Simões, 1954.

SUNKEL, Osvaldo; PAZ, Pedro. El subdesarrollo latinoamericano y la teoría del 
MAGALHÃES FILHO, F. B. B. de. Origens da integração do Cone Sul...

desarrollo. México: Siglo Veintiuno, 1970.

WESTPHALEN, Cecília Maria. Comércio exterior do Brasil meridional. Curitiba: CD. 1999.

ZWEIG, Stefan. Fernão de Magalhães: história da primeira circunavegação. Rio de Janeiro: Guanabara, 1938. 